\title{
Finite Element Analysis of Nylon Based 3D Printed Autonomous Underwater Vehicle Propeller
}

\author{
H.M.T. Khaleed ${ }^{a}$, Irfan Anjum Badruddin ${ }^{b}$, A.N. Saquib ${ }^{a}$, Ali E. Anqi ${ }^{b}$, Vineet Tirth ${ }^{b^{*}}$ (D) M.F. Addas ${ }^{a}$, \\ Faisal O. Mahroogi ${ }^{a}$, Sarfaraz Kamangar ${ }^{b}$, T.M. Yunus Khan ${ }^{b}$, Amro Hamada Ma, Amin A.G. Haider \\ ${ }^{a}$ Islamic University in Madinah, Faculty of Engineering, Department of Mechanical Engineering, \\ Madinah Munawwarra, Kingdom of Saudi Arabia \\ ${ }^{b}$ King Khalid University, College of Engineering, Department of Mechanical Engineering, P.O. Box 394, \\ Abha 61421, Kingdom of Saudi Arabia
}

Received: June 1, 2020; Revised: September 4, 2020; Accepted: September 26, 2020

\begin{abstract}
The recent developments in the additive manufacturing to manufacture complex cost effective profiles is gaining popularity to test the strength of developed products through finite element method (FEM). Finite element analysis (FEA) is a potent tool for mechanical analysis. The combination of 3D printing and FEA is opening new opportunities to go further in the complexity of the product geometry. The autonomous underwater vehicle (AUV) propeller blade has a complex profile with multi-directional gradient and twist, which requires a multi-stage operation to manufacture, including the hubs. The AUV propeller is required to withstand the applied load and generate the required thrust to move AUV at the desired speed. The current study explores the performance of AUV propeller prepared by additive synthesis using Nylon 6 material. The design of the propeller blade was developed using SOLID WORKS and integrated to the CUBPRO (DUO) to obtain the required 3D printing parameters. A comparative investigation is made for Nylon material within the dimensional conformance with the 3D printed propeller blade. The stress-strain analysis of the Nylon AUV propeller is carried with the FEM. The analysis of error and the stress show that the Nylon material meets the performance criteria for AUV propeller.
\end{abstract}

Keywords: Nylon, Additive Manufacturing, FDM, AUV Propeller, FEM.

\section{Introduction}

Development of modular propeller blades for an autonomous underwater vehicle (AUV) with conventional methods are laborious, time-consuming, and result in excessive material wastage. Manufacturing of complex profile with conventional manufacturing techniques has several limitations. To meet the current market demand, changes in the design is a routine exercise. It is cumbersome to make changes in the design of a product due to the cost of tooling and multiple stages of manufacturing in conventional manufacturing processes. The additive manufacturing (AM) is successfully used in making sophisticated and complex products with a high degree of dimensional stability. 3D printing (3DP) is a technique of AM. A few products popularly made by AM are biomedical instruments with relatively versatile profiles $^{1,2}$ and microfluidic products ${ }^{3}$. The AM is a flexible process capable of developing extremely complex profiles and geometries with a variety of materials like metals, polymers, ceramics, etc. ${ }^{4}$. Researchers and engineers have successfully used different AM methods to develop a variety of products. A few widely used AM processes are Selective Laser Sintering (SLS) ${ }^{5-7}$, Fused Deposition Modelling (FDM $)^{8}$, Stereolithography ${ }^{9-11}$, etc.

*email: v.tirth@gmail.com
In FDM, extrusion of a semi-molten state string is done in a thermo-plastic state. As the material ejects from the nozzle, it is deposited in layers on a substrate to develop the desired shape according to the geometrical details of the model generated by Computer-Aided Design (CAD) ${ }^{12}$. The deposition of the layer by layer material is continued in steps until the desired thickness is achieved. The substrate, which is also known as the base plate, is lowered by a fixed value after each step to enable the deposition of the subsequent layer ${ }^{13}$. The 3D computer aided design (CAD) model is hence printed by FDM easily and quickly ${ }^{14}$. A few challenges in the development of the product by FDM include the precise process control to obtain accurate dimensions of the part, the level of interlayer bonding, and printing defects such as porosity, under/mis-extrusions airgaps, and smooth laminar deposition of the material, etc. The minor error in the process control may lead to micro-gaps in part due to air entrapment. The problem of air entrapment may be removed during the heat treatment of the part by incorporating the microspheres, which are expanded in response to the heat treatment and arrest the air gaps ${ }^{15-17}$. Optimum process control and printing in a controlled environment are effective to address these challenges.

In the Stereolithography process, a low-intensity laser is employed to cure the photosensitive liquid resin and make 
it hard layer-by-layer, as it is deposited. The final shape of the part is exactly as per the geometry of the CAD model. The two main issues observed in the Stereolithography process are inferior mechanical properties and the time consumed in curing ${ }^{18}$. SLS is another popular AM technique, which has three mechanisms of binding the materials, namely, full melting, solid-state sintering and liquid phase sintering. In SLS, the raw material may be a metal, polymer, resin or powder. The raw material is exposed to high-intensity directional heating resulting in its full or partial melting and fusion to take the shape of the $3 \mathrm{D}$ model ${ }^{19,20}$. Rapid tooling and producing components with complicated geometries according to the CAD model is possible with 3DP. A range of raw materials can be transformed into products with $3 \mathrm{DP}$. It is becoming a versatile technique to develop intricate shapes, day-by-day. The developed products must be tested for strength either by experimental methods or by any proven simulation technique. However, the flexibility provided by $3 \mathrm{DP}$ to develop a realistic model with any imagination puts restrictions on the experimental testing ability of the model. This difficulty can be easily addressed by FEA where the task is further simplified since the same geometric model can be used for 3DP as well as the FEA. Thus, the combination of 3DP and FEA has huge implications on the design and developments of future products.

The propeller of AUV has a complicated geometry. The engineers and researchers have developed complicated profiles of products such as aero foils, propellers, turbine blades, etc. with many methods, but these involve a series of stages and are quite time-consuming. These stages are labor-intensive and also result in poor quality control and increased cost. The 3DP may be a more suitable technique than the conventional manufacturing processes to develop its complex shape. In a study, Khaleed et al. ${ }^{21}$ suggested a five-stage cold forging process to optimize the size of a preform for complex AUV propeller. This process was both costly and time-consuming. Recent study ${ }^{22}$ suggested that the complex shape of AUV propeller can be developed through 3DP. Thus this field is open to be utilized even to prepare intricate profiles of underwater vehicles. However, the search for materials that can withstand the high pressure arising at the propeller blades as well as that can resist the corrosive characteristics of seawater would motivate future research. Khaleed et al. ${ }^{23}$ developed propeller blades using AISIAL6061 as the workpiece material and die steel (AISID2) as the die material to obtain the optimum workpiece dimensions. The modelling and simulations were performed on SOLIDWORK SSP47.2007 and DEFORMF33D, respectively.

Samad et al. ${ }^{24}$ worked on a modular approach to enhance the manufacturability of AUV propeller parts and to simplify their configurations. The error assessment in cold forged part is essential because of the spring back action of aluminium material ${ }^{25}$. Abbot et al. ${ }^{26}$ worked on 3DP, which has grown tremendously over the past few years and continues to do so as the industry grows with new technologies. To perform FEA analysis, the Autodesk Inventor was used, and the comparison was made among the simulated and experimental test results, but the results were contrasting ${ }^{26}$. Zur ${ }^{27}$ presented the FEA of PLA based 3DP parts and performed shape optimization.
The static bending test was carried out, followed by FEA on Siemens NX software with Nastran module of FEM analysis. The weight of the blades was successfully reduced at the optimized shape to withstand applied forces from theoretical, simulation, and experimental observation. Cojocaru ${ }^{28}$ analyzed infill matrix for the internal volume because infill matrix can have different geometries and different degrees of filling by the FEM. The stresses and deformations appear in a sample with a rectilinear infill. The influence of infill parameters on the mechanical properties of the parts was studied using eighteen distinct geometries. FEM is an effective and reliable tool for stress analysis in isotropic, orthotropic, and composite materials $^{29}$.

Nylon seems to have both of these properties along with its easy to use characteristics for 3DP. Thus, the current work aims to test the capability of $3 \mathrm{D}$ printed AUV propeller made from Nylon 6. In this exploratory study, modular AUV propeller has been developed with AM using FDM, which is suitable for short lead time and cost-efficient prototypes ${ }^{30}$. The propeller blade is analyzed for strength and stress-strain distribution by FEA.

\section{Methodology}

\section{(A) Solid Modelling and analysis of AUV propeller blade}

Designing of the AUV propeller is the challenging task since propeller blades have a very complex profile. A 3D CAD model with hexahedron free mesh configuration was developed using SOLID WORKS SP47 to ensure mesh independence in the propeller blades for $\mathrm{AUV}^{22}$. For the analysis of the metal forming process and the temperature raised during the forming process, DEFORM-F33D simulation tool was used. Nylon (polyamide) is used in the automobile industry in making structural components such as door handles, consoles, radiator grills etc. Other applications of Nylon are in making engineering products, namely, gears, joints, pedals, covers, underwater pipes, agricultural fittings, and fasteners. Good tensile and impact strengths, resistance to chemicals and corrosion, and compatibility with 3DP makes it a suitable material for FDM of engineering products. Among different types of Nylons, Nylon 12, Nylon 6/6, and Nylon 6 were considered as a candidate material for FDM. The properties of Nylon 6 and Nylon 6/6 are nearly the same, and Nylon 6 was introduced as a new FDM material by Stratasys Inc. in 2016. On comparing the key mechanical properties of Nylon 6 with Nylon 12, it was revealed that the Nylon 6 has complete dominance over Nylon 12. It has about 50\% higher tensile strength, $8 \%$ higher elongation, $80 \%$ higher elastic modulus, $60 \%$ high flexural strength, $80 \%$ high flexural modulus, $67 \%$ high impact strength, and 10\% higher creep resistance ${ }^{31}$. Nylon 6 is resistant to brine, it can withstand high pressure, and it offers a combination of good tensile properties with toughness, so it was selected as the material for FDM filament. Nylon 6 filament roll having a fixed diameter of $0.7 \mathrm{~mm}$ and weight per roll $650 \mathrm{gm}$, purchased from 3D system CUBEPRO DUO was used as the feedstock. The properties of Nylon 6 are given in Table 1 . 
The FEA of the blade was done to analyze the strength of the blade using the Autodesk Inventor module, which has the properties of Nylon 6 in its data bank. The load applied on the surface of the blade was $1.5 \mathrm{kN}$ while its tail end in all the directions was constrained. The analysis carried out was anisotropic due to the nature of the 3DP blade. After the FEA results were found satisfactory, the 3D model was transformed into the 3DP machine CubePro DUO, supplied by 3D Systems Inc., shown in Figure 1. To ensure the proper deposition, complete fusion and eliminate the possibility of air entrapment, the 3DP machine configuration was carefully selected as given in Table 2. A layer resolution of $200 \mu \mathrm{m}$

Table 1. The properties of Nylon 6.

\begin{tabular}{|c|c|c|}
\hline Category & Property & Value \\
\hline \multirow{3}{*}{ General } & Density & $1.13 \mathrm{~g} / \mathrm{cm}^{3}$ \\
\hline & Ultimate Tensile Strength & $82.68 \mathrm{MPa}$ \\
\hline & Yield Strength & $82.75 \mathrm{MPa}$ \\
\hline \multirow{3}{*}{ Stress } & Elastic Modulus & $2.93 \mathrm{GPa}$ \\
\hline & Modulus of Shear & $1.08519 \mathrm{GPa}$ \\
\hline & Poisson's Ratio & 0.35 \\
\hline
\end{tabular}

Table 2. The 3DP Machine configuration.

\begin{tabular}{cc}
\hline Parameter & Description \\
\hline Maximum build size & $242.9 \mathrm{~mm}(\mathrm{w}) \times 270.4 \mathrm{~mm}(\mathrm{l}) \times 230 \mathrm{~mm}(\mathrm{~h})$ \\
\hline Mode & Custom \\
\hline Layer resolution & $200 \mu$ \\
\hline Print strength & Solid \\
\hline Print pattern & Diamond \\
\hline Print material & Nylon \\
\hline Support material & Nylon \\
\hline Sidewalk material & Nylon \\
\hline Fill spacing & $2 \mathrm{~mm}$ \\
\hline Sidewalk distance & $3 \mathrm{~mm}$ \\
\hline Sidewalk layers & 2 \\
\hline Sidewalk offset & $0.15 \mathrm{~mm}$
\end{tabular}

was maintained. 3DP was done in a closed chamber to reduce any chances of contamination or porosity.

\section{(B) Procedure for 3DP of AUV propeller blade by FDM}

The 3DP process in FDM was accomplished in three stages. Stage one included the pre-processing. In this stage, the 3D CAD model in the SLDPRT format was saved. The .STL (Standard Tessellation Language) was prepared to convert the file format received from CAD model and the printer was configured with a proprietary BUILD file *.cubepro, exported to the 3DP machine. Stage two included the command-based decisions, on the part material, support material and configuration, and the resolution and strength of the print. The 3DP machine was configured, and a built plate (substrate) consisting of two layers, the top layer or print pad (polymer) sitting over a glass base was prepared. The platform was levelled and glued, and the 3DP process was executed thereafter ${ }^{32}$. Stage three was the post-processing where the supports were removed, and the 3DP part was extracted from the platform. There were some irregularities in the part, such as the layer lines, roughness, etc., which were removed, and the 3DP part was smoothened. The 3DP configuration settings include nozzle diameter of $0.7 \mathrm{~mm}$, extruder temperature of $230^{\circ} \mathrm{C}$, platform (bed) temperature between $35-40{ }^{\circ} \mathrm{C}$, depending on the ambient temperature, and print speed of $15 \mathrm{~mm} / \mathrm{s}$.

\section{(C) Profile comparison and error measurement}

The comparison of the profile of the model and the 3DP part was made to determine any deviation or error in the profile. Visual inspection is the first step in this process to ensure the uniformity and integrity of the part and to ascertain that the part is free from any visible defect. To check the dimensional conformity of the 3DP blade, it was compared with the CAD model, followed by a two-step quality control process. Firstly, the cross-section of the 3DP blade was analyzed using ImageJ image-processing software. Later,

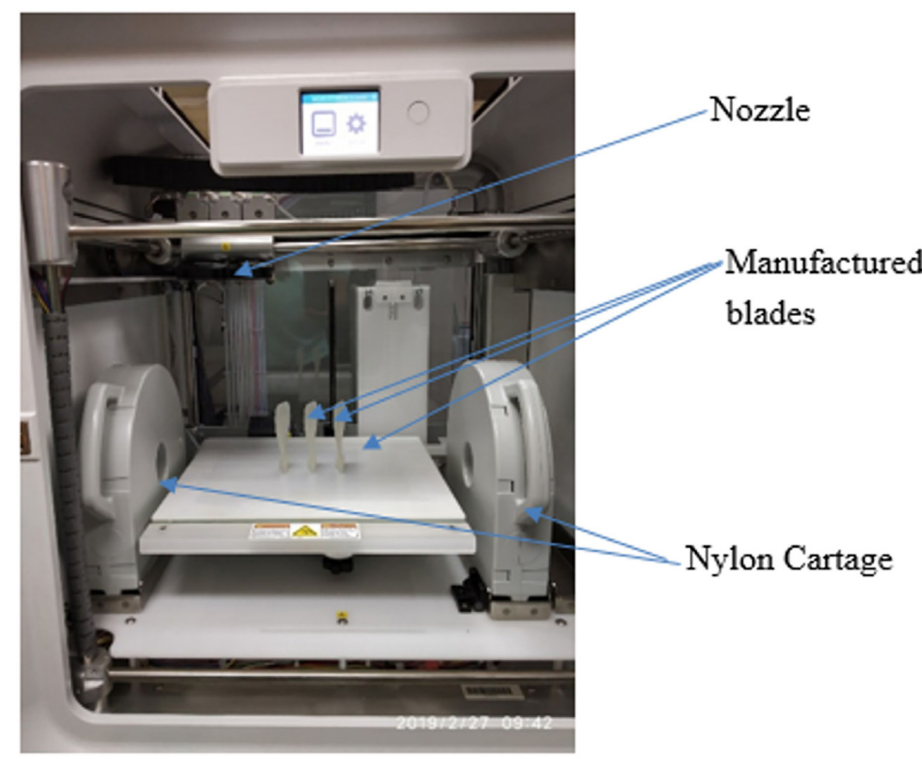

Figure 1. Picture of the CubePro Duo FDM based 3D printer made by company 3D Systems, while the blades are being printed. 
the area and perimeter of the part were physically measured and compared with that of the 3D model. Inclusion of pores in the material during the $3 \mathrm{DP}$ process may result in the reduction in density. To determine the integrity of the 3DP material, the density of 3DP blades was determined using the weight loss method and compared with the theoretical density of the Nylon 6.

\section{Results and Discussion}

\section{(A) FEM analysis}

The conventional materials used for making the AUV propeller are Aluminium alloys and Cast iron. But despite the addition of corrosion-resistant materials and coatings, the corrosive degradation of the propeller is common ${ }^{32}$. A simplified FEA model was analyzed to a single orientation of the blade. The boundary conditions applied in FEM analysis in the INVENTOR package on the propeller blade are shown in Figure 2. As expected, it may be observed that maximum stresses accrued at the fixed end, while maximum displacement is at the anterior end.

The distribution of stresses in the blade is shown in Figure $3 \mathrm{a}$ for the applied load. The stress and strain are in the permissible range. The maximum stress is $5.77 \mathrm{MPa}$ which appears in a small section of the blade, shown in the inset in Figure 3a. Therefore, it has conclusively emerged that 3DP Nylon blade is safe since its yield strength given in Table 1 is much higher. The maximum stress is only $7 \%$ of the yield strength of Nylon. The analysis of stress at this blade orientation indicates that the stresses are expected to be within the endurance limits of the blades in other orientations as well. The deflection of the blade under the applied loads is shown in Figure 3b. The maximum deflection is determined

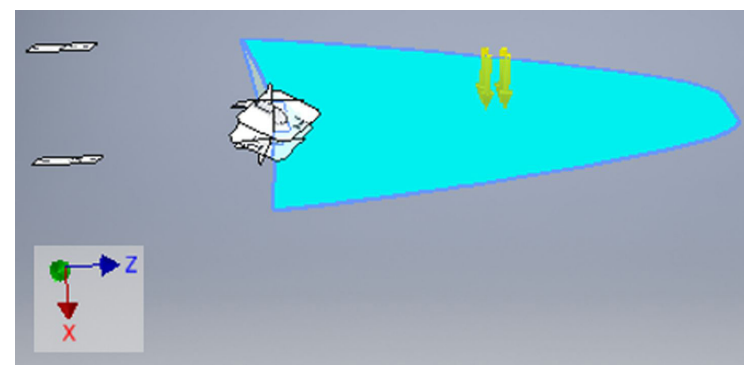

Figure 2. Boundary conditions applied to the model of the blade. as $0.01387 \mathrm{~mm}$ at the anterior end of the blade, which is as per the expectation since the other end of the blade was fixed. This maximum deflection is well within the permissible range as per the properties of Nylon 6 . The error estimated by Equation 1 is $10.5 \%$, which is acceptable.

$$
\delta B=W L^{3} / 6 E I
$$

In Equation 1, $\delta \mathrm{B}$ is the deflection, $W$ is the load applied on the blade, $L$ is the length of the blade, $I$ is the moment of inertia, and $E$ is the elastic modulus.

\section{(B) FDM process}

The three 3DP blades were assembled with the hub to make the AUV propeller. Modular blades and the hub is shown in Figure 4. In an earlier study ${ }^{22}$, the AUV propeller was manufactured in five stages, shown in Figure 5. In contrast, in the present study, the 3DP AUV propeller is made in one single operation with ease using FDM, compared with the conventional method. The conventional method includes more time, material wastage, the skill of machinist, and is a labor-intensive process. This results in higher costs with inferior quality. On large scale production and rapid prototyping, the FDM process can be highly cost-efficient. The weight of the 3DP Nylon 6 propeller is about $60 \%$ of the Aluminium alloys and only $20 \%$ of Cast Iron. Therefore the 3DP Nylon 6 blades will reduce the payload on the AUV considerably.

\section{(C) Error Measurement}

Geometrical analysis of the 3DP Nylon 6 impeller blades was carried out by measurement of the cross-section at three different distances from the tip of the blade and a comparison was made with the cross-sections of the CAD model. The truncation scheme is shown in Figure 6. Three blades truncated at the specified distances were $3 \mathrm{D}$ printed with a $2 \mathrm{x}$ scale, as shown in Figure 7 . The measurement of the cross-sections was completed with desired images processed in image processing software, ImageJ. The comparison between the CAD model and the 3D printed truncated models was made for cross-sectional area and perimeter as summarized in Table 3. Visual comparison for shape conformity was also made and is shown in Figure 8. Considering the cross-sectional area, the $3 \mathrm{D}$ printed models show a near consistent error of $20 \%$ compared to the CAD model, which is taken as reference. Visual inspection of the

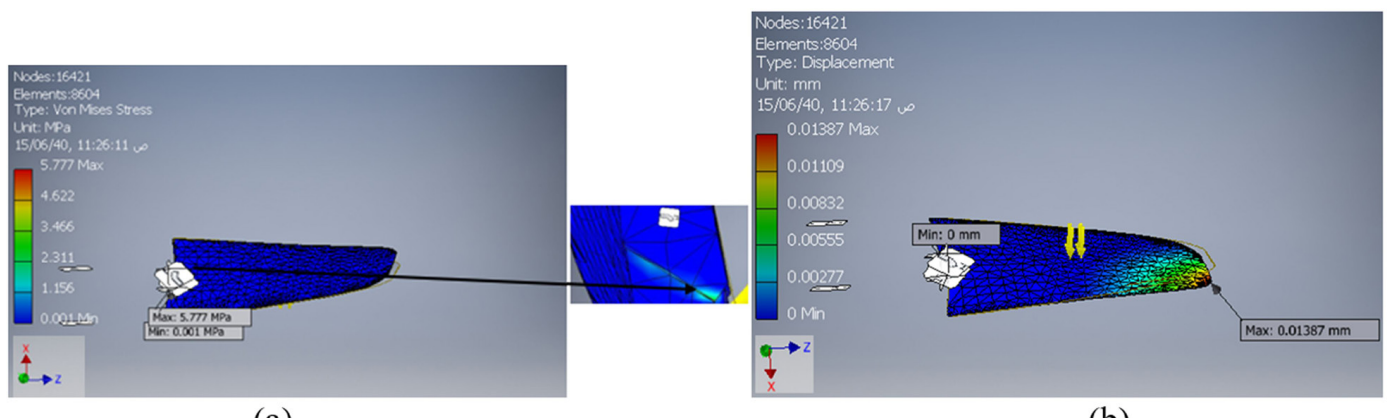

(a)

(b)

Figure 3. (a) Stress contours and Von Mises stress distribution in the blade. (b) The deflection of the blade under the applied loads. 
Table 3. The deviations in the perimeters of the $3 \mathrm{D}$ printed models as compared to the CAD models.

\begin{tabular}{|c|c|c|c|c|c|c|}
\hline \multirow{2}{*}{$\begin{array}{l}\text { Distance from } \\
\text { blade tip }(\mathrm{mm})\end{array}$} & \multicolumn{2}{|c|}{ Area $\left(\mathrm{mm}^{2}\right)$} & \multirow{2}{*}{ Error (\%) } & \multicolumn{2}{|c|}{ Perimeter (mm) } & \multirow{2}{*}{ Error (\%) } \\
\hline & CAD & 3D Model & & CAD & 3D Model & \\
\hline 15 & 48.326 & 38.998 & 19.303 & 84.380 & 93.943 & -11.333 \\
\hline 30 & 83.178 & 63.294 & 23.905 & 91.580 & 101.772 & -11.129 \\
\hline 45 & 112.769 & 90.659 & 19.607 & 88.407 & 99.825 & -12.915 \\
\hline
\end{tabular}

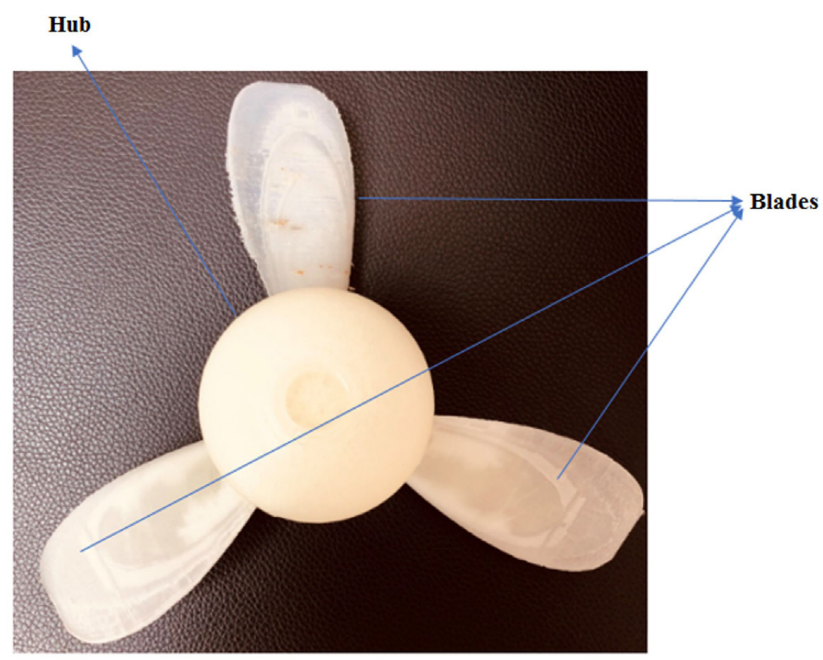

Figure 4. Assembled AUV Propeller.

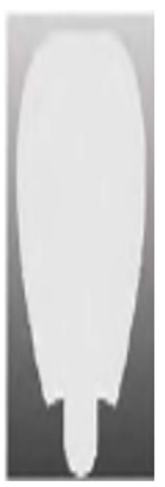

Blanking

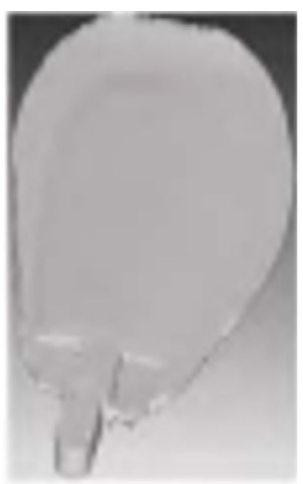

Forging

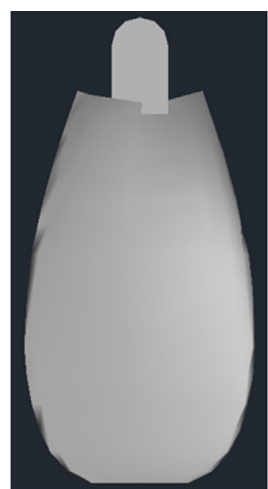

Shearing

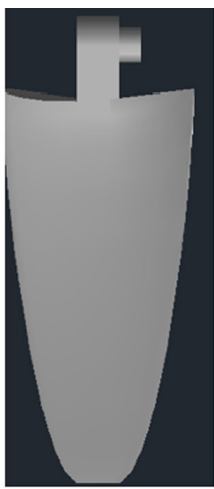

Embossing

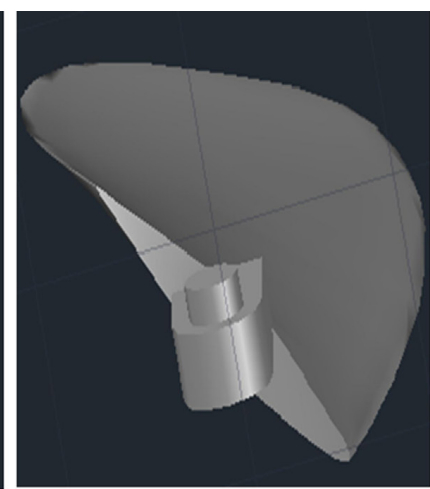

Twisting

Figure 5. Stages of manufacturing of conventional propeller blade.

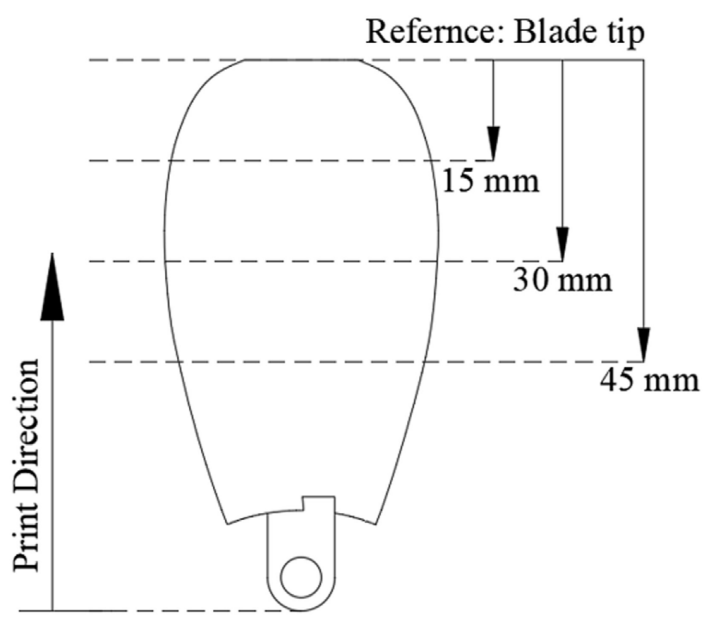

Figure 6. Reference and truncation of the 3D printed Impeller Blade. 


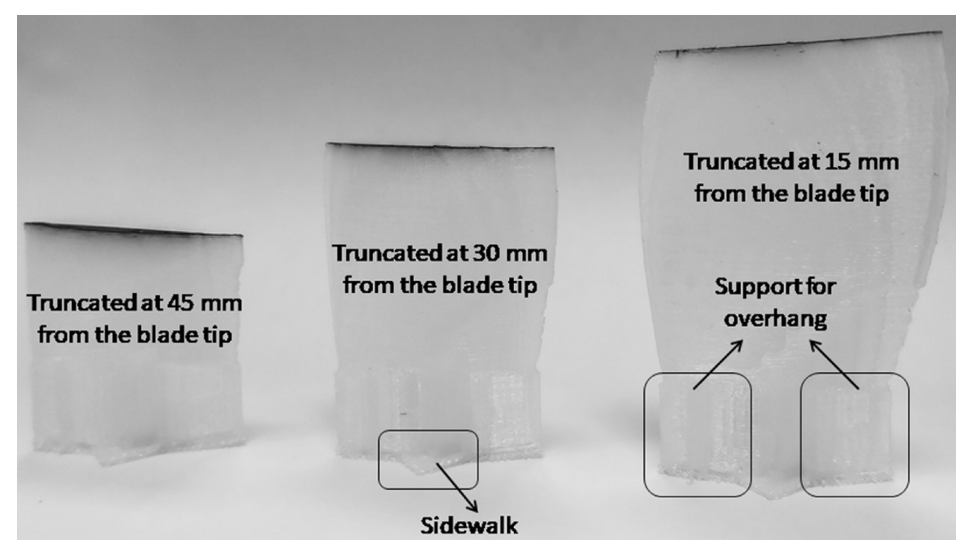

Figure 7. Three blades truncated at the specified distances were 3D printed.

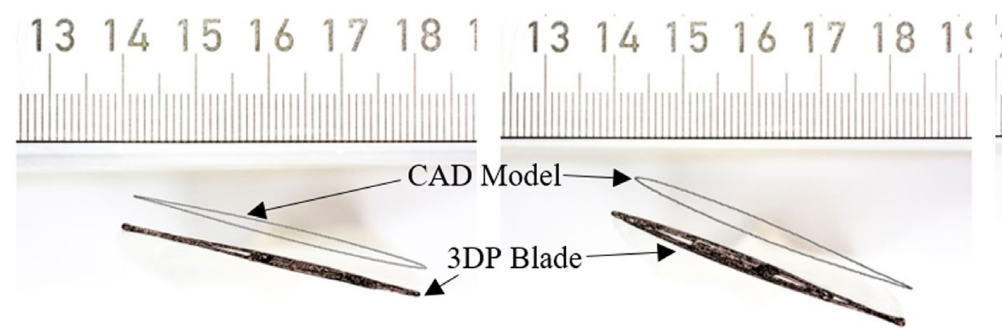

(a) $15 \mathrm{~mm}$

(b) $30 \mathrm{~mm}$

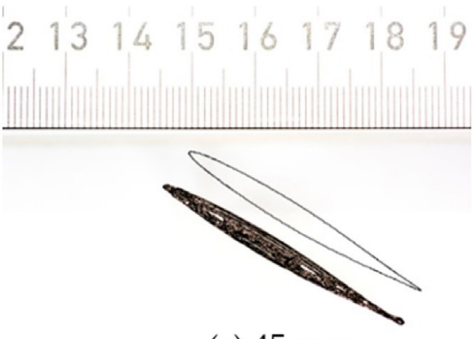

(c) $45 \mathrm{~mm}$

Figure 8. Shape comparison between 3D printed model sections and CAD sections.

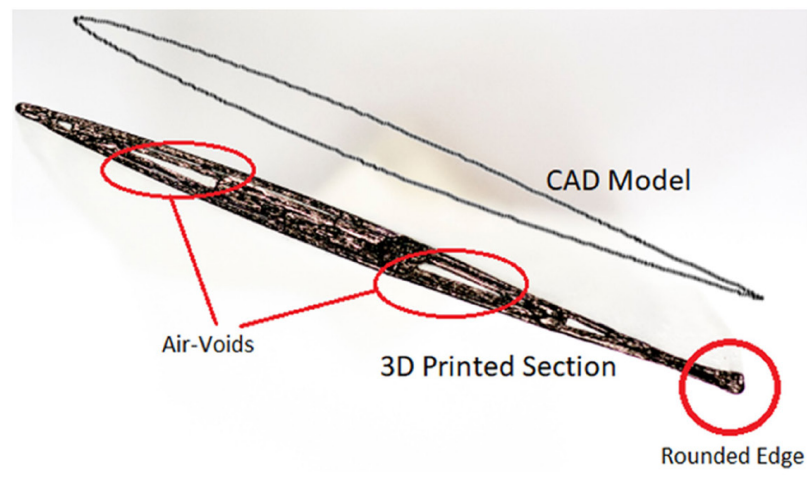

(a)

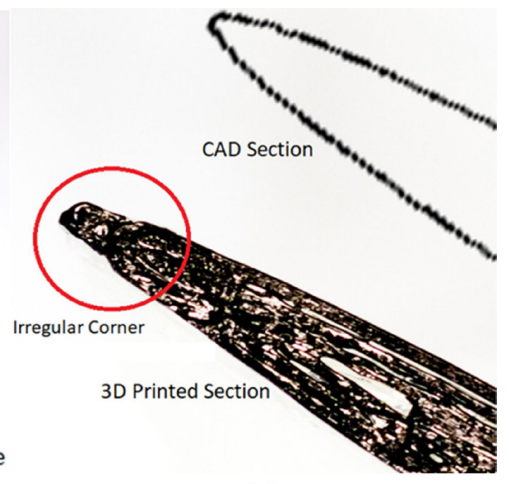

(b)

Figure 9. (a) Defects in 3D Printed Models. (b) Irregular geometry with the small rounded feature.

models reveals two reasons for the deviation of the printed models from the CAD model. Firstly, the thin edge witnessed in the CAD model in Figure 8, could not be reproduced in the $3 \mathrm{D}$ model, primarily due to the inherent limitations in FDM process or the selected resolution of the machine configuration. Such rounding of edges is inevitable in FDM prints with the layer resolution of $200 \mu \mathrm{m}$. Secondly, the traces of air-voids appear in the first two truncations, i.e. at 15 and $30 \mathrm{~mm}$. These are thinner sections than the third truncated section at $45 \mathrm{~mm}$.

To determine the presence of air voids, the density of the blades was measured, and the average density was found to be $1.09 \mathrm{~g} / \mathrm{cm}^{3}$. The difference between the theoretical density of the Nylon 6 and the 3DP blade is $+0.04 \mathrm{~g} / \mathrm{cm}^{3}$, which is quite reasonable. From the density measurement and careful observations of Figure 7 and 8; it may be established that the pores are present in limited volume and are confined only to the thinner sections of the blades. Thinner sections cause difficulties in the layering of the fused material resulting in a poor deposition. These air-voids allow the 3DP parts to shrink, accounting for smaller cross-sections. Even the thicker edge is not as smooth because the movement resolutions limit small and smooth features, as shown in Figure 9a. Hence the vertical edges created with the layer resolution limitations cannot be as smooth as in the CAD model as observed from Figure $9 \mathrm{~b}$ and Figure 10.

The deviations in the perimeters of the $3 \mathrm{D}$ printed models as compared to the CAD models are given in Table 3 . The deviation in the area is consistent between 19-23\% and that in the perimeter is consistent between $11-13 \%$. The perimeter of the $3 \mathrm{D}$ printed model sections being larger than that of the CAD model is largely attributed to rounding of the edges as visible from Figure 10. 


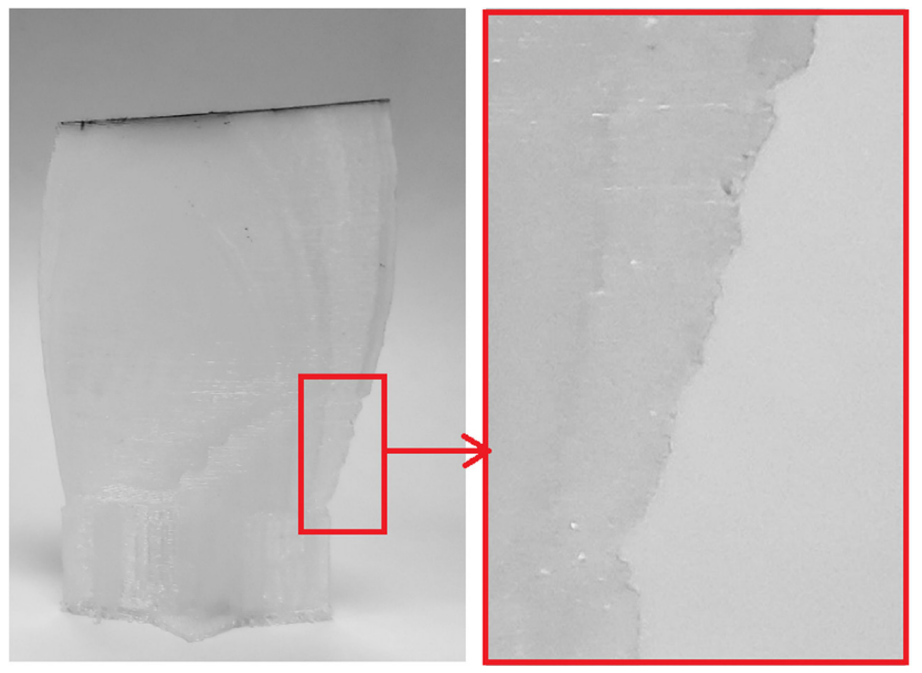

Figure 10. Rough Vertical Edge on the Thin Side.

\section{Conclusions}

In a single operation, the propeller for AUV was developed by $3 \mathrm{D}$ printing. It is observed by the stress analysis that the propeller made from Nylon 6 can easily endure the underwater loads on the blades of the propeller. The maximum stresses appear on the fixed end, and the maximum deflection occurs at the free end. The maximum stress is only $7 \%$ of the yield stress of Nylon, making it a promising candidate material for making the AUV propeller. The error between the required model and the physical model is consistent. A few deviations are observed in the 3DP model, in particular in the thinner sections, which may be fixed by increasing the printing resolution and a few post-processing finishing operations. The 3DP Nylon 6 propeller is a promising and cost-efficient solution for AUV for large scale production.

\section{Acknowledgement}

The authors extend their appreciation to the Deanship of Scientific Research at King Khalid University (KKU), Abha, Kingdom of Saudi Arabia for funding this work through research groups program under grant number R.G.P.1/201/41.

\section{References}

1. Brunello G, Sivolella S, Meneghello R, Ferroni L, Gardin C, Piattelli A, et al. Powder-based 3D printing for bone tissue engineering. Biotechnol Adv. 2016;34(5):740-53. http://dx.doi. org/10.1016/j.biotechadv.2016.03.009.

2. Ahangar P, Cooke ME, Weber MH, Rosenzweig DH. Current biomedical applications of 3D printing and additive manufacturing. Appl Sci (Basel). 2019;9(8)

3. Vancauwenberghe V, Baiye Mfortaw Mbong V, Vanstreels E, Verboven P, Lammertyn J, Nicolai B. 3D printing of plant tissue for innovative food manufacturing: encapsulation of alive plant cells into pectin based bio-ink. J Food Eng. 2019;263:454-64.

4. Chen Z, Li Z, Li J, Liu C, Lao C, Fu Y, et al. 3D printing of ceramics: a review. J Eur Ceram Soc. 2019;39(4):661-87.

5. Khan SZ, Masood SH, Cottam R. Mechanical properties of a novel plymetal manufactured by laser-assisted direct metal deposition. Int J Adv Manuf Technol. 2017;91(5-8):1839-49.
6. Lahtinen E, Precker RLM, Lahtinen M, Hey-Hawkins E, Haukka M. Selective Laser Sintering of Metal-Organic Frameworks: Production of Highly Porous Filters by 3D Printing onto a Polymeric Matrix. ChemPlusChem. 2019;84(2):222-5.

7. Yan C, Hao L, Hussein A, Young P, Huang J, Zhu W. Microstructure and mechanical properties of aluminium alloy cellular lattice structures manufactured by direct metal laser sintering. Mater Sci Eng A. 2015;628:238-46. http://dx.doi. org/10.1016/j.msea.2015.01.063.

8. Ivanov E, Kotsilkova R, Xia H, Chen Y, Donato RK, Donato K, et al. PLA/Graphene/MWCNT composites with improved electrical and thermal properties suitable for FDM 3D printing applications. Appl Sci (Basel). 2019;9(6)

9. Melchels FPW, Bertoldi K, Gabbrielli R, Velders AH, Feijen J, Grijpma DW. Mathematically defined tissue engineering scaffold architectures prepared by stereolithography. Biomaterials. 2010;31(27):6909-16. http://dx.doi.org/10.1016/j. biomaterials.2010.05.068.

10. Park HK, Shin M, Kim B, Park JW, Lee H. A visible light-curable yet visible wavelength-transparent resin for stereolithography 3D printing. NPG Asia Mater. 2018;10(4):82-9.

11. Sano Y, Matsuzaki R, Ueda M, Todoroki A, Hirano Y. 3D printing of discontinuous and continuous fibre composites using stereolithography. Addit Manuf. 2018;24:521-7. http:// dx.doi.org/10.1016/j.addma.2018.10.033.

12. Gültekin HE, Tort S, Acartürk F. An effective technology for the development of immediate release solid dosage forms containing low-dose drug: fused deposition modeling 3D printing. Pharm Res. 2019;36(9)

13. Hu B, Duan X, Xing Z, Xu Z, Du C, Zhou H, et al. Improved design of fused deposition modeling equipment for $3 \mathrm{D}$ printing of high-performance PEEK parts. Mech Mater. 2019;137:103139. http://dx.doi.org/10.1016/j.mechmat.2019.103139.

14. Ahmed GMS, Badruddin IA, Tirth V, Algahtani A, Ali MA. Wear resistance of maraging steel developed by direct metal laser sintering. Mater Express. 2020;10(7):1079-90.

15. Wang J, Xie H, Weng Z, Senthil T, Wu L. A novel approach to improve mechanical properties of parts fabricated by fused deposition modeling. Mater Des. 2016;105:152-9. http:// dx.doi.org/10.1016/j.matdes.2016.05.078.

16. Sood AK, Ohdar RK, Mahapatra SS. Improving dimensional accuracy of Fused Deposition Modelling processed part using grey Taguchi method. Mater Des. 2009;30(10):4243-52. http:// dx.doi.org/10.1016/j.matdes.2009.04.030. 
17. Nouri H, Guessasma S, Belhabib S. Structural imperfections in additive manufacturing perceived from the X-ray microtomography perspective. J Mater Process Technol. 2016;234:11324. http://dx.doi.org/10.1016/j.jmatprotec.2016.03.019.

18. Manapat JZ, Chen Q, Ye P, Advincula RC. 3D printing of polymer nanocomposites via stereolithography. Macromol Mater Eng. 2017;302(9):1-13.

19. Vaezi M, Seitz H, Yang S. Erratum to: a review on 3D micro-additive manufacturing technologies. Int J Adv Manuf Technol. 2013;67(5-8):1721-54. http://dx.doi.org/10.1007/ s00170-012-4605-2.

20. Eshraghi S, Das S. Mechanical and microstructural properties of polycaprolactone scaffolds with one-dimensional, twodimensional, and three-dimensional orthogonally oriented porous architectures produced by selective laser sintering. Acta Biomater. 2010;6(7):2467-76. http://dx.doi.org/10.1016/j. actbio.2010.02.002.

21. Khaleed HMT, Samad Z, Othman AR, Mujeebu MA, Abdullah $\mathrm{AB}$, Zihad MM. Work-piece optimization and thermal analysis for flash-less cold forging of AUV propeller hubs-FEM simulation and experiment. J Manuf Process. 2011;13(1):41-9. http://dx.doi.org/10.1016/j.jmapro.2010.10.003.

22. Khaleed HMT, Badruddin IA, Saquib AN, Addas MF, Kamangar S, Yunus Khan TM. Novel approach to manufacture an AUV propeller by additive manufacturing and error analysis. Appl Sci (Basel). 2019;9(20)

23. Khaleed HMT, Samad Z, Mujeebu MA, Abdullah AB. Flash-less cold forging of AUV propeller blade: work-piece optimization and thermal analysis. Arab J Sci Eng. 2013;38(9):2509-19.

24. Samad Z, Abdullah AB, Khaleed HMT, Abu-Bakar MH, Arshad MR. A novel manufacturing method of propeller for autonomous underwater vehicle (auv) using cold forging process. Indian J Geo-Mar Sci. 2012;41(3):242-8.

25. Abdullah AB, Sapuan SM, Samad Z, Khaleed HMT, Aziz NA. Manufacturing of AA6061 propeller for AUV application using cold forging process. Sci Res Essays. 2012;7(2):170-6.

26. Abbot DW, Kallon DVV, Anghel C, Dube P. Finite element analysis of 3D printed model via compression tests. Procedia Manuf. 2019;35:164-73. https://doi.org/10.1016/j. promfg.2019.06.001.

27. Żur P. Finite elements analysis of pla 3d-printed elements and shape optimization. Eur J Eng Sci Technol. 2019;1-7.

28. Cojocaru V. Influence of rectilinear infill parameters on mechanical behavior of 3D printed parts - a fem approach. Robotica \& Management. 2019;24(2), 4-7.

29. Begum S, Ahmed GMS, Badruddin IA, Tirth V, Algahtani A. Analysis of digital light synthesis based flexible and rigid polyurethane for applications in automobile bumpers. Mater Express. 2019;9(8):839-50.

30. Tan DK, Maniruzzaman M, Nokhodchi A. Advanced pharmaceutical applications of hot-melt extrusion coupled with fused deposition modelling (FDM) 3D printing for personalised drug delivery. Pharmaceutics. 2018;10(4), 203.

31. Computer Aided Technology. Stratasys 3D Printing: Nylon 12 vs. the New Nylon 6 - FDM Printers. Illinois: Computer Aided Technology; 2016 [cited 2020 May 21]. Available from: https://www.cati.com/blog/2016/12/nylon-12-vs-thenew-nylon-6-for-stratasys-fdm-printers/

32. Salazar R, Campos A, Fuentes V, Abdelkefi A. A review on the modeling, materials, and actuators of aquatic unmanned vehicles. Ocean Eng. 2019;172:257-85. http://dx.doi. org/10.1016/j.oceaneng.2018.11.047. 